\title{
Determination of the barakol content of mature leaves, young flowers of Senna siamea (Lam.) Irwin and Barneby and in the herbal recipes
}

\author{
Chaowalit Monton ${ }^{1,2^{*}}$, Laksana Charoenchai ${ }^{1,2^{*}}$, Poj Kulvanich ${ }^{1}$, Jirapornchai Suksaeree ${ }^{1,2}$ and Krisana Kraisintu ${ }^{2,3}$
}

\begin{abstract}
Background: Barakol, a major substance from Senna siamea (Lam.) Irwin and Barneby, is found in variable amount depending upon the source of the plant. Scientific evidence to characterize the traditional preparation of S. siamea is needed. The aim of this study was to characterize the content of barakol in various plant sources and to validate the high-performance liquid chromatography (HPLC) method for the quantification of barakol content from plants harvested from five locations in the northeast of Thailand and in several herbal recipes in which S. siamea is one of the constituents.
\end{abstract}

Methods: Barakol was extracted from fresh young leaves of S. siamea and identified by chromatographic and spectroscopic techniques. Barakol content in mature leaves and young flowers of $\mathrm{S}$. siamea harvested from five northeastern provinces in Thailand and its content in herbal recipes were quantified by validated HPLC. Separation was performed using C18 column and gradient elution of ultrapure water and methanol. Three herbal recipes containing S. siamea were studied to select the suitable solvent with which to extract barakol.

Results: Barakol was verified and its content determined using a validated HPLC method with a good linearity $\left(R^{2}=0.9999\right)$, accuracy (\%recovery $=99.25$ to $\left.101.59 \%\right)$, and precision (\%RSD $\left.<2 \%\right)$ including limit of detection (LOD) and limit of quantitation (LOQ) (16.80 and $5.04 \mathrm{ng} / \mathrm{mL}$, respectively). The average barakol content in mature $S$. siamea leaves and young flowers was 0.300 and $0.279 \% \mathrm{~W} / \mathrm{W}$, respectively. Boiling water extracts yielded the highest barakol content in three herbal recipes $(0.077,0.123$, and $0.085 \% \mathrm{~W} / \mathrm{W})$.

Conclusions: Boiling water was an appropriate solvent to maximize barakol yield from herbal recipes containing $S$. siamea from Surin mature leaves and Yasothorn young flowers.

Keywords: Barakol; Senna siamea; Herbal recipe; Insomnia

\section{Background}

Many people around the world suffer from sleeping disorders of which insomnia is the most common. Insomnia is divided into three categories: difficulty falling asleep (sleep onset disturbance), difficulty remaining asleep (sleep maintenance disturbance), and poor quality (nonrestorative) sleep (Walsh 2004). This problem adversely affects daytime functioning and may lead to anxiety, depression, pain, and

\footnotetext{
* Correspondence: chaowalit@rsu.ac.th; laksana39@hotmail.com

'Faculty of Pharmacy, Rangsit University, Muang, Pathum Thani 12000, Thailand ${ }^{2}$ Sino-Thai Traditional Medicine Research Center (cooperation between Rangsit University, Harbin Institute of Technology, and Heilongjiang University of Chinese Medicine), Rangsit University, Muang, Pathum Thani 12000, Thailand

Full list of author information is available at the end of the article
}

increased risk of cardiovascular events, especially myocardial infarction (Morphy et al. 2007; Westerlund et al. 2013). Furthermore, home-, work-, and auto-related accidents are associated with sleep disturbance (Leger et al. 2014).

Senna siamea (Lam.) Irwin and Barneby is widely cultivated in Southeast Asia, including Thailand. Barakol has been recognized as a major biologically active component of flowers and young leaves of $S$. siamea. Fresh, young leaves of S. siamea contain approximately $0.40 \% \mathrm{w} / \mathrm{w}$ barakol (2,5-dimethyl-3aH-pyrano[2,3,4-de]-1-benzopyran-3a,8diol, $\mathrm{Mw}=232$ ) (Padumanonda and Gritsanapan 2006). Barakol is an unstable, tricyclic ring structure that is converted to anhydrobarakol $(\mathrm{Mw}=214)$ by loss of one molecule of water (Thongsaard et al. 2001). The conversion 


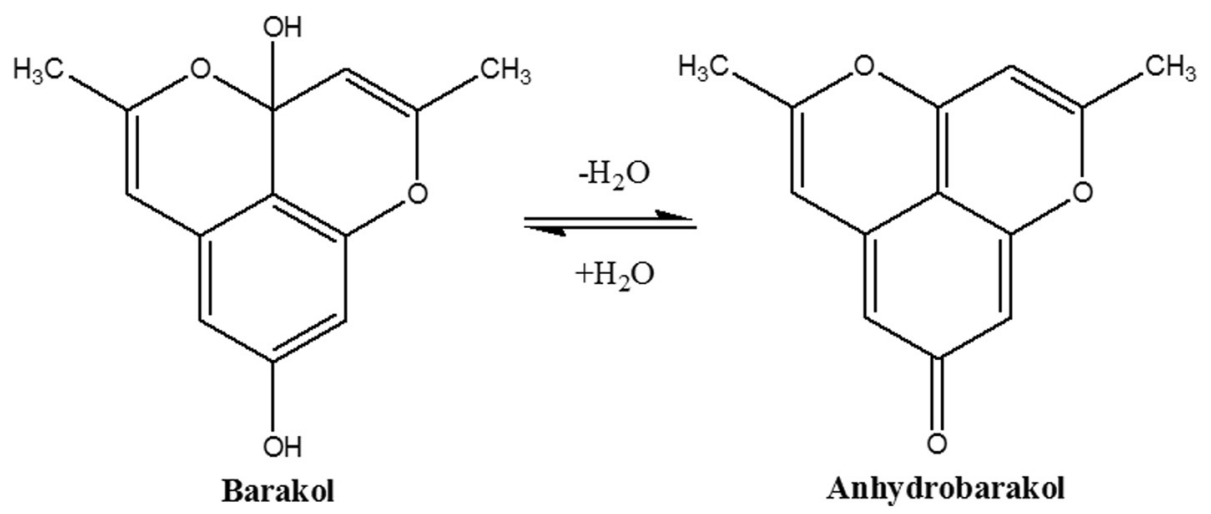

Figure 1 Chemical structure and conversion of barakol and anhydrobarakol (reproduced with permission) (Thongsaard et al. 2001).

from barakol to anhydrobarakol is shown in Figure 1. Barakol exhibits hypnotic effect in both animals and human volunteers and has been used as a medicinal agent by insomniacs. But, the Food and Drug Administration of Thailand removed the products containing S. siamea leaves from the market due to their hepatotoxicity (Chantong et al. 2009).

Many Chinese medicines comprised of herb combination are purported to offer synergism of therapeutic efficacy while lessening adverse effects (Yang et al. 2014). Thai traditional medicines often include a combination of herbs to theoretically optimize efficacy and minimize side effects. Whether such benefits, particularly with regard to hepatotoxicity of barakol, are derived from preparations containing S. siamea have not been scientifically demonstrated in controlled clinical trials. In order to ultimately enable in vivo investigation of the efficacy and safety of such preparations, we sought to standardize the mythology for characterization of barakol content of $S$. siamea and several herbal preparations. This paper reports on the characterization of two herbs containing S. siamea leaves. Seeds of Senna tora (Linn.) Roxb. and aerial parts of Leonurus sibiricus Linn were used. Firstly, extraction and quantification of barakol from fresh young leaves of $S$. siamea served as a standard. Secondly, comparisons were made of the barakol content of mature leaves and young flowers of S. siamea harvested from five different locations in Northeast Thailand using a validated high-performance liquid chromatography (HPLC) method. We then determined the solvent that yielded the greatest extraction of barakol from three S. siamea containing herbal recipes.

\section{Methods}

Plant materials and reagents

Mature leaves and young flowers of S. siamea were harvested from five locations in Northeast Thailand: (1) Muang district, Nakorn Ratchasima province; (2) Prakonchai district, Buriram province; (3) Buached district, Surin province; (4) Kamkuankaew district,
Yasothorn province; and (5) Panomprai district, Roi Et province. Samples were harvested on 9 to 10 November 2013. The leaves and flowers of each source were harvested from the same tree. Samples from different locations were coded as NR, BR, SR, YS, and RE, respectively. Seeds of $S$. tora and aerial part of L. sibiricus were purchased from Chareonsuk Osod, Nakon Pathom province, Thailand. Water was purified by Puris, Expe-UP water system (model: Expe-UP series, Korea). All organic solvents were analytical grade obtained from Burdick and Jackson, Korea.

\section{Extraction of barakol from S. siamea leaves}

Barakol was extracted from fresh young leaves of S. siamea as previously reported (Wongtongtair et al. 2011). The fresh young leaves of $S$. siamea $(1,000 \mathrm{~g})$ were chopped into small pieces and boiled in $2,000 \mathrm{~mL}$ of $0.5 \%$ sulfuric acid for $30 \mathrm{~min}$, then filtered with filter cloth. The residue was reboiled using the same method. The filtrates were combined, filtered, and alkalinized with $10 \%$ sodium hydrogen carbonate. The solution was partitioned three times with dichloromethane. The dichloromethane part was concentrated with rotary evaporator (Buchi, Thailand). An equal volume of cold water was gently added and the product cooled in a refrigerator for $30 \mathrm{~min}$. Crystallized greenish-yellow needles of crude barakol were obtained. They were collected by vacuum filtration, washed with little amount of dichloromethane and cold water, dried, and kept in a desiccator until used.

\section{Identification of isolated barakol}

Five different methods including thin layer chromatography (TLC), high-performance liquid chromatography (HPLC) and ultraviolet (UV) spectrophotometry, infrared (IR) spectrometry, nuclear magnetic resonance (NMR), and mass spectrometry (MS) were used to identify the isolated barakol.

\section{TLC}

Chromatography was performed on a TLC precoated silica gel $60 \mathrm{GF}_{254}$ plate $20 \times 10 \mathrm{~cm}$ (Merck, Germany). 
Chloroform-methanol mixture $(85: 15, v / v)$ was used as a mobile phase (Padumanonda et al. 2007) with 20-mL total volume. Three barakol tracks were applied using capillary tube and kept dry under ambient temperature. The TLC plate was developed in the TLC chamber and equilibrated with the mobile phase for $45 \mathrm{~min}$ before use. After the plate was developed, it was dried under ambient temperature and read at $366 \mathrm{~nm}$ UV light with a TLC visualizer (Camag, Muttenz, Switzerland). The test was performed in triplicate and the retention factor $\left(R_{\mathrm{f}}\right)$ was calculated.

\section{HPLC chromatogram and UV spectrum}

Barakol was prepared in methanol in concentration of $20 \mu \mathrm{g} / \mathrm{mL}$. Samples were analyzed by HPLC as describe below. One peak of barakol should be found. UV spectra of barakol were scanned between 200 and $400 \mathrm{~nm}$ by diode-array detector. The maximum absorbance was collected.

\section{IR spectrometry}

Approximately $200 \mathrm{mg}$ of potassium bromide powder was ground. Two milligrams of barakol was blended with potassium bromide powder. The mixture was then compressed into pellet by hydraulic press with 8 tons force. FT-IR spectra were collected between 4000 and $400 \mathrm{~cm}^{-1}$ by accumulating 32 scans with the resolution of $16 \mathrm{~cm}^{-1}$ on the Nicolet 6700 spectrometer (Thermo Scientific, Waltham, MA, USA). Spectra were processed with the OMNIC 8.0 software (Thermo Scientific, USA).

\section{NMR spectrometry}

NMR data of barakol was recorded in $\mathrm{CDCl}_{3}$ on a Fourier Transform NMR spectrometer (Unity Inova, Varian, Darmstadt, Germany), operating at $500 \mathrm{MHz}$ for both protons and carbons.

\section{Mass spectrometry}

The LC-MS studies were performed by coupling the LC system with a Dionex Ultimate 3000 . A Luna C18 column $(250 \times 4.60 \mathrm{~mm}$ i.d., $5 \mu \mathrm{m})$ equipped with $10 \times 4.6 \mathrm{~mm}$ i.d. guard column was controlled at $25^{\circ} \mathrm{C}$. The injection volume was $5 \mu \mathrm{L}$. The flow rate was $0.4 \mathrm{~mL} / \mathrm{min}$. The mass determinations were made in alternative ESI mode in the mass range of 100 to $2000 \mathrm{amu}$ (Bruker Amazon SL, Münster, Germany).

\section{HPLC conditions}

HPLC analyses were performed on an Agilent 1260 series equipped with photodiode array detector and autosampler. Data analysis was carried out using OpenLab CDS EZChrom software (Agilent, USA). Separation was performed at $25^{\circ} \mathrm{C}$ on a Luna C18(2) column $(250 \times 4.60 \mathrm{~mm}$ i.d., $5 \mu \mathrm{m}$ ). The mobile phase consisted of water (A) and methanol (B). The gradient program went from $100 \%$ to 95\% A in 5 min and holding for 2 min, decreased to $90 \%$ $\mathrm{A}$ in $3 \mathrm{~min}$, decreased to $60 \% \mathrm{~A}$ in $15 \mathrm{~min}$, and then decreased to $30 \% \mathrm{~A}$ in $30 \mathrm{~min}$ and holding for $3 \mathrm{~min}$. The post run was set to decrease to $0 \% \mathrm{~A}$ and equilibrate for $10 \mathrm{~min}$ before the next injection. The mobile phase flow rate was $1 \mathrm{~mL} / \mathrm{min}$. The injection volume was $10 \mu \mathrm{L}$. The quantitation wavelength was set at $245 \mathrm{~nm}$.

\section{Standard barakol preparation}

Standard barakol stock solution was prepared in methanol at concentration of $0.4 \mathrm{mg} / \mathrm{mL}$. Standard barakol should be freshly prepared to avoid chemical degradation.

\section{Method validation}

Linearity was determined at six concentrations of standard barakol between 0.25 and $40.0 \mu \mathrm{g} / \mathrm{mL}$ in methanol. Precision (intra-day and inter-day) was studied at three concentrations of barakol, 2.50, 5.00, and $10.00 \mu \mathrm{g} / \mathrm{mL}$, and reported as percentage relative standard deviation (\%RSD). Accuracy was evaluated by addition of three barakol concentrations $(2.50,5.00$, and $10.00 \mu \mathrm{g} / \mathrm{mL})$ with known amount of barakol to sample solutions. Percentage recovery of barakol was reported. The limit of quantitation (LOQ) and limit of detection (LOD) were studied based on visual evaluation between signal and noise. The standard barakol solution was diluted with methanol until signal-tonoise ratios were 10 and 3, respectively. Furthermore, specificity, robustness, and system suitability were evaluated. In the case of robustness, changing the flow rate by \pm 0.2 $\mathrm{mL} / \mathrm{min}$, column temperature by $\pm 2^{\circ} \mathrm{C}$, and wavelength by $\pm 2 \mathrm{~nm}$ were performed.

\section{Quantification of barakol in samples}

Dried mature leaves and young flowers of S. siamea were ground and sieved through 40-mesh sieve. The samples were individually extracted in $95 \%$ ethanol. Two grams of sample were extracted with $50 \mathrm{~mL}$ of $95 \%$ ethanol by sonication for $1 \mathrm{~h}$. The sample was filtered through filter paper to obtain $95 \%$ ethanol extract solution. Then, the solvent was eliminated from the extract by evaporation under vacuum condition. Percentage yield was collected and extracts were kept in desiccator until used. Absolute ethanol was used as solvent when samples were prepared for HPLC analysis to obtain $500 \mu \mathrm{g} / \mathrm{mL}$ of sample.

The three herbal recipes were coded as F1, F2, and F3. The ingredients, part used, and weight ratio of herbal recipes are shown in Table 1 . Each herb was individually ground and sieved through 40-mesh sieve. Then, herbs were mixed together by the geometric dilution method to obtain herbal recipes. In F1 formula, 3 g were dissolved in $50 \mathrm{~mL}$ of four solvent systems: boiling water, water at ambient temperature, $60 \%$ ethanol, and $95 \%$ ethanol. F2 and F3 were extracted in two solvent systems: boiling water 
Table 1 Ingredients, part used, and weight ratio of herbal recipes

\begin{tabular}{llll}
\hline Formula & Ingredients & Part used & Weight ratio \\
\hline F1 & S. siamea (Lam.) & Leaves & 1 \\
& Irwin and Barneby & & \\
& S. tora (Linn.) Roxb. & Seeds & 1 \\
& L. sibiricus Linn. & Aerial parts & 2 \\
F2 & S. siamea (Lam.) & Leaves & 1 \\
& Irwin and Barneby & & \\
& S. tora (Linn.) Roxb. & Seeds & 3 \\
F3 & S. siamea (Lam.) & Leaves & 1 \\
& Irwin and Barneby & & \\
& L. sibiricus Linn. & Aerial parts & 3 \\
\hline
\end{tabular}

and $95 \%$ ethanol. All formulas were extracted by sonication at ambient temperature for $1 \mathrm{~h}$. The sample was filtered through filter paper to obtain extract solution. The solvent was eliminated from the extract by evaporation under vacuum condition for ethanol-based extract and freeze-dried condition for water-based extract. Percentage yield was collected and extracts were kept in desiccator until used. Water-based extracts were dissolved in water while ethanol-based extract were dissolved in absolute ethanol to obtain $500 \mu \mathrm{g} / \mathrm{mL}$ of sample. All samples were filtered through a $0.2-\mu \mathrm{m}$ nylon membrane before injection into the HPLC instrument. Peak area-under-the-curve of barakol was compared to the calibration curve and calculated into barakol content in dry plant per weight basis.

\section{Results and discussion}

\section{Identification of extracted barakol}

The five methods of identification of extracted barakol are reported. From TLC technique, the extracted barakol showed a single band with $R_{\mathrm{f}}=0.48 \pm 0.01$. UV spectrum with maximum wavelengths at 242 and $372 \mathrm{~nm}$ revealed that some chromophores were related to the benzene ring and conjugated double bonds of barakol. The HPLC chromatogram showed that a sharp peak of barakol eluted at retention time of $30.9 \mathrm{~min}$. HPLC chromatogram of barakol is shown in Figure 2a.

The IR spectrum (Figure 3) of isolated barakol exhibited a broad band of hydroxyl group (-OH) at 2,800 to 3,600 $\mathrm{cm}^{-1}$. A sharp peak at $1,676.75 \mathrm{~cm}^{-1}$ represented stretching vibration of $-\mathrm{C}-\mathrm{C}=\mathrm{C}-\mathrm{O}-$. A strong peak at $1,578.79 \mathrm{~cm}^{-1}$ and another at $1,564.91 \mathrm{~cm}^{-1}$ were characteristic of aromatic rings. The last strong peak at $1,465.55 \mathrm{~cm}^{-1}$ represented C-H stretching.

${ }^{1} \mathrm{H}$-NMR spectrum showed two chemical shifts at 1.534 and $2.391 \mathrm{ppm}$ indicating two hydroxyl protons. Two chemical shifts at 2.206 and $2.335 \mathrm{ppm}$ indicated two methyl protons. Four chemical shifts at 5.954, 6.222, 6.260 , and $6.368 \mathrm{ppm}$ indicated four methylene protons. ${ }^{13} \mathrm{C}$-NMR spectrum showed two chemical shifts at
19.200 and 20.640 ppm indicating methyl carbons. Eleven chemical shifts at 98.303, 104.422, 106.627, 107.762, $114.808,130.921,153.484,158.245,159.208,166.115$, and $183.620 \mathrm{ppm}$ indicated 11 aromatic carbons. The ${ }^{1} \mathrm{H}-\mathrm{NMR}$ and ${ }^{13} \mathrm{C}$-NMR spectra are shown in Figures 4 and 5, respectively.

MS spectra showed mass-to-charge ratio $(\mathrm{m} / \mathrm{z})$ of 233 in positive ESI mode representing the molecular weight of barakol (232). All identification data were similar to standard barakol reported in previous publications (Padumanonda et al. 2007; Chantong et al. 2009). The identification results indicated that the extracted chemical constituent from fresh young leaves of S. siamea was barakol.

\section{HPLC method validation}

A linear correlation between peak area-under-the-curve and barakol concentration was in the range of 0.25 to $40.0 \mu \mathrm{g} /$ $\mathrm{mL}$. The linear equation of standard curve of barakol $y=123274 x+14155$ exhibited good linearity $\left(R^{2}=0.9999\right)$. The specificity was tested by observing UV spectrum of extracted barakol in the beginning, middle, and end of the barakol peak. The data revealed that all three points of the spectrum of barakol peak had the same pattern. In addition, a blank, the standard, and the plant extract were injected into HPLC and their chromatograms were confirmed. The results showed that the barakol peak was no interference of blank solution peak at the retention time of barakol indicating that the analytical method was valid. For intra- and inter-day precision, \%RSD was less than $2 \%$. The analytical method exhibited good accuracy with percent recovery of 99.25 to $101.59 \%$. The precision and accuracy are shown in Table 2. The concentration of barakol was diluted until the signal-to-noise ratios were 10:1 and 3:1 indicating that LOQ and LOD were 16.80 and $5.04 \mathrm{ng} / \mathrm{mL}$, respectively.

For robustness test, the three parameters were studied: flow rate, column temperature, and detection wavelength. The \%RSD of peak area and \%RSD of retention time were less than 2\% (Table 3), indicating the analytical method was robust. In addition, the system suitability data showed that \%RSD of all parameters from six replicate injections was less than $2 \%$. The theoretical plates were 102,425 (more than 2000) and asymmetry or tailing factor was 1.74 (less than 2) for the barakol peak. The system suitability results are shown in Table 4 .

\section{Quantification of barakol content}

The mature leaves and young flowers of S. siamea were harvested from five locations in Northeast Thailand and coded as NR, BR, SR, YS, and RE. Percent yields of these plants, which were extracted by $95 \%$ ethanol, were in the range of 10 to $16 \%$. The extraction yields of S. siamea leaves were approximately 11 to $14 \%$ (average $12.32 \%$ ) in comparison to the flower extract of 10 to $16 \%$ (average 


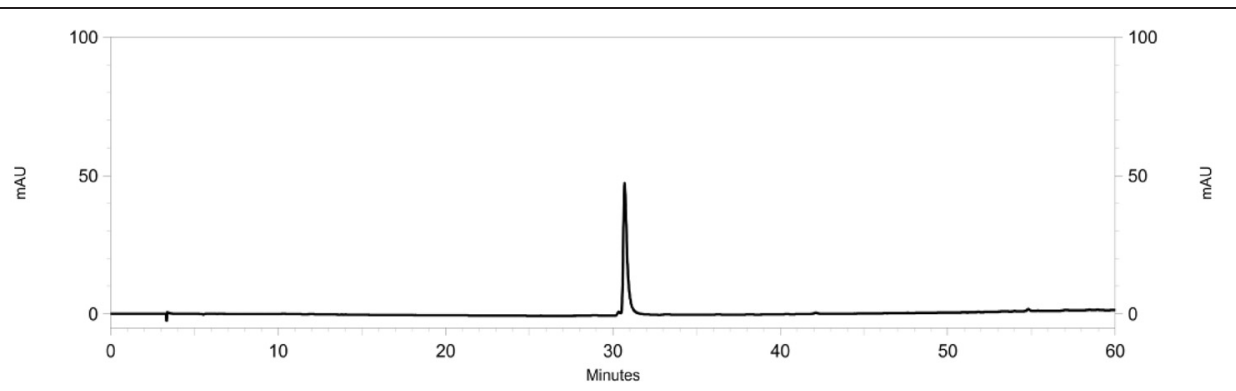

(a)

20

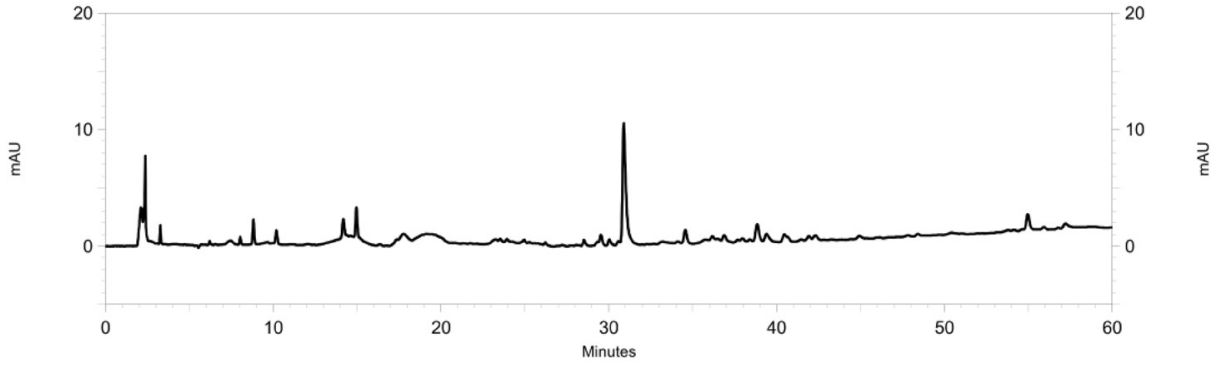

(b)

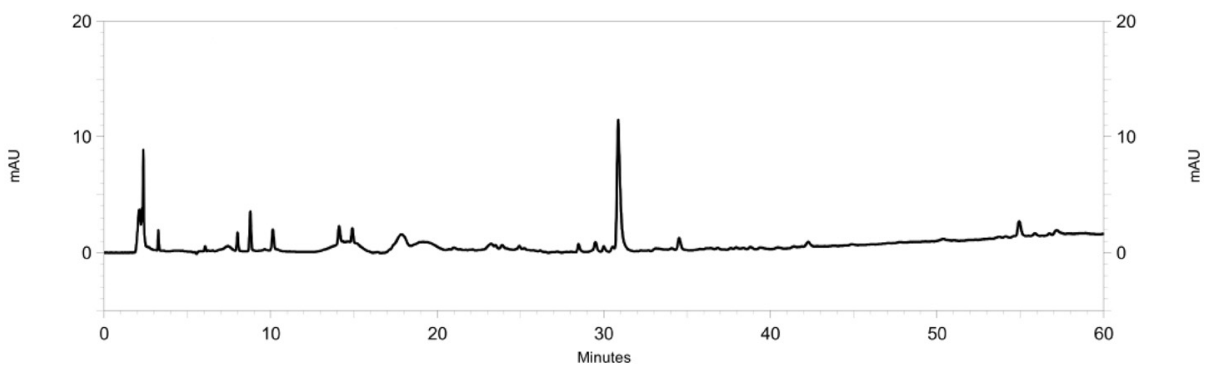

(c)

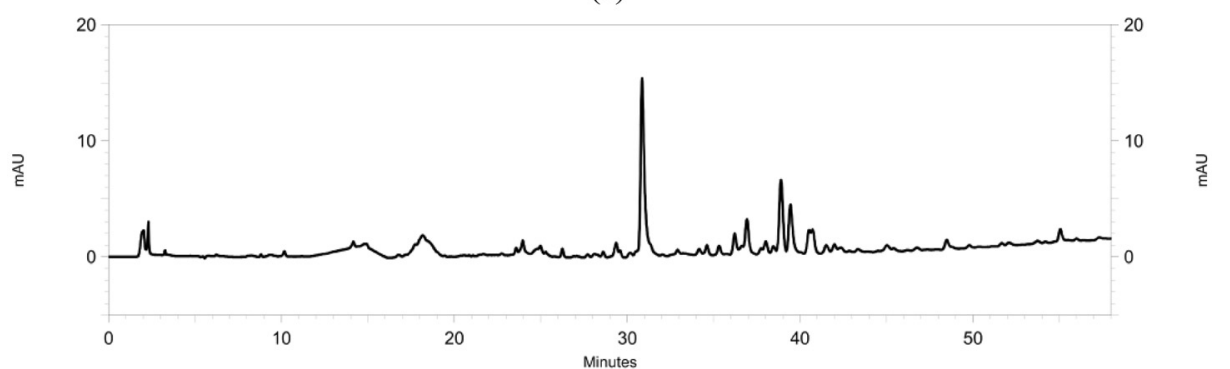

(d)

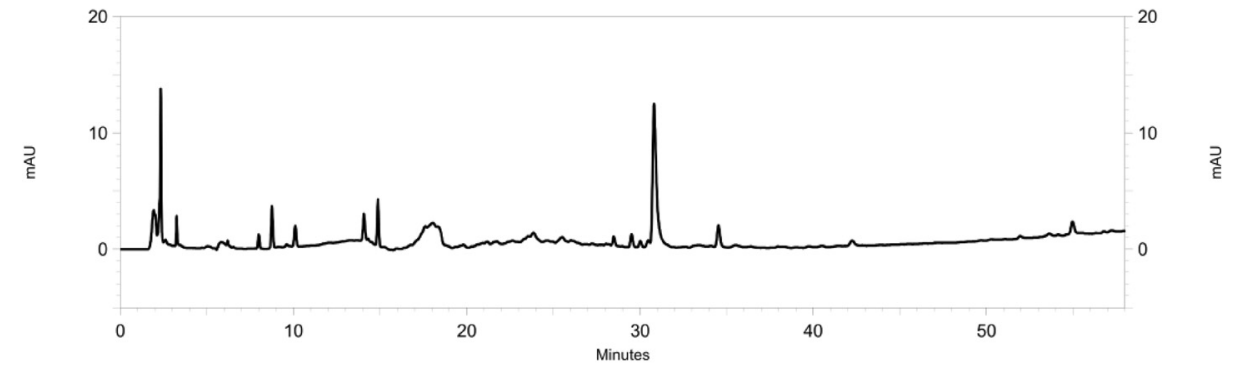

(e)

Figure 2 HPLC chromatogram of barakol (a), boiling water extract (b) and water extract of F1 (c), boiling water extract of F2 (d) and F3 (e). 


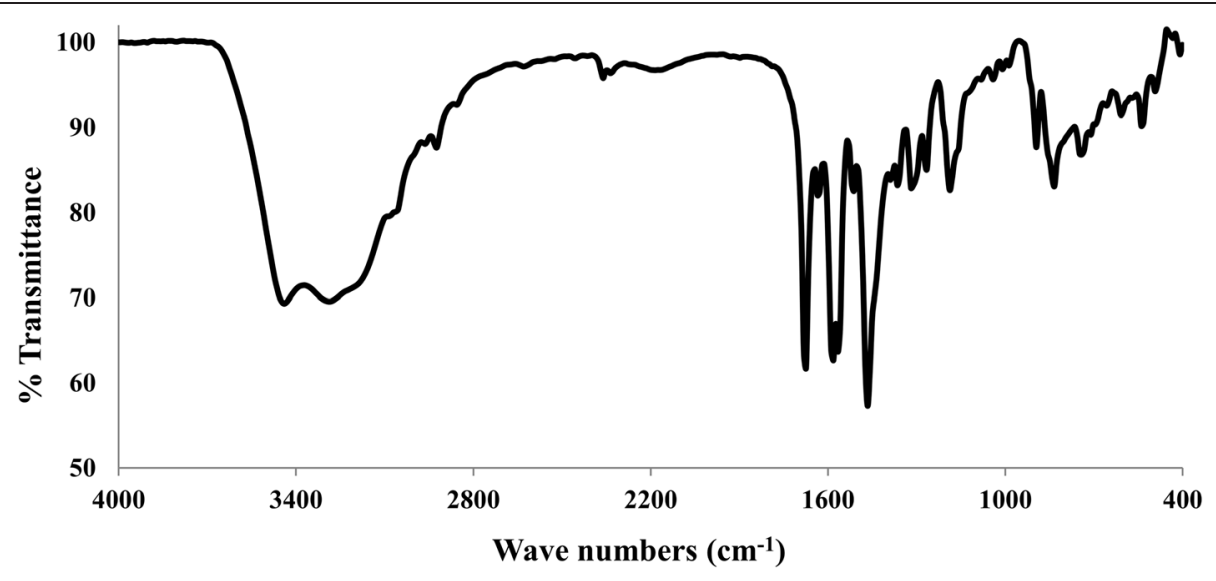

Figure 3 IR spectrum of barakol.

12.64\%). Barakol content in leaves of S. siamea on dry weight basis ranged from 0.043 to $0.617 \% \mathrm{w} / \mathrm{w}$. The lowest barakol content was found in mature leaves of NR $(0.043 \pm 0.005 \% w / w)$. The highest barakol content was found in SR mature leaves $(0.617 \pm 0.072 \% w / w)$ and YS young flowers $(0.398 \pm 0.026 \% w / w)$. Ranking of barakol content in S. siamea mature leaves was $\mathrm{SR}>\mathrm{RE}>\mathrm{YS}>$ BR $>$ NR. The average barakol content in S. siamea mature leaves was $0.30 \% w / w$, which was slightly less (approximately $0.40 \% w / w$ ) than in fresh young leaves reported

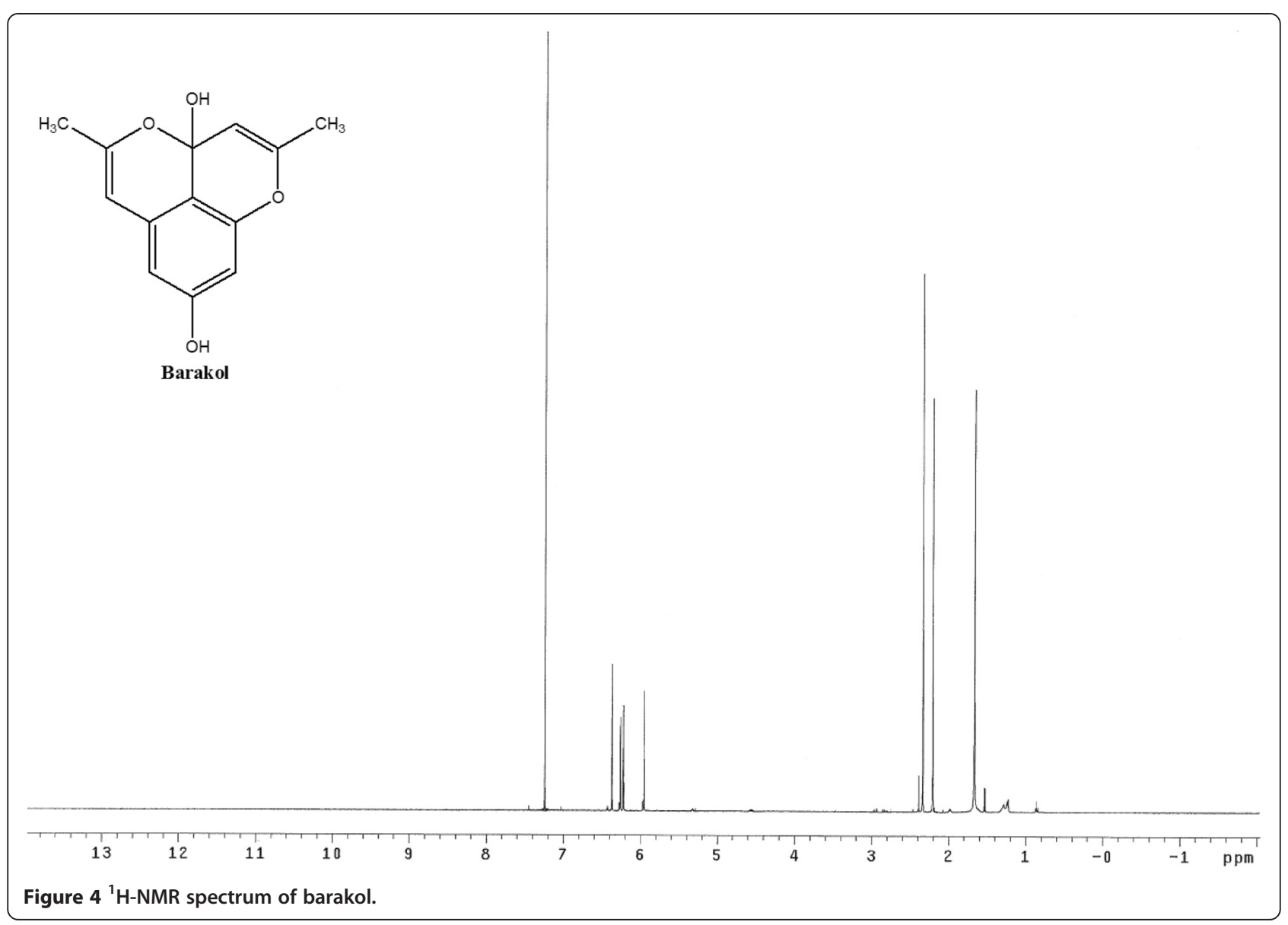




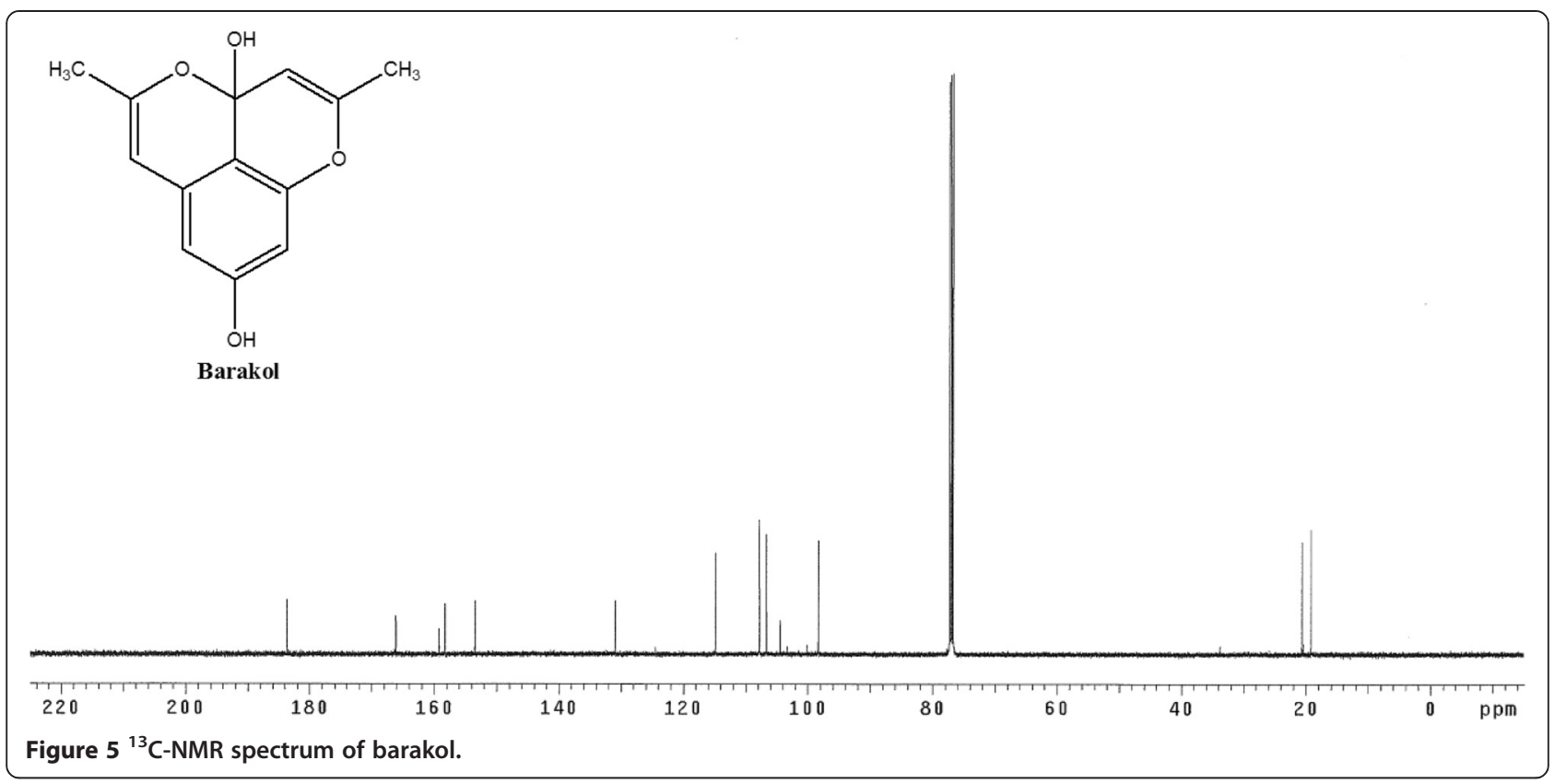

previously (Padumanonda and Gritsanapan 2006). For $S$. siamea young flowers, barakol content ranged between 0.189 and $0.398 \% w / w$ with an average value of $0.279 \% w /$ $w$. Ranking of barakol content in young flowers of S. siamea was $\mathrm{YS}>\mathrm{SR}>\mathrm{RE}>\mathrm{BR}>\mathrm{NR}$ (Table 5). The barakol content of $S$. siamea mature leaves $(0.30 \pm 0.23 \% \mathrm{w} / \mathrm{w})$ and young flowers $(0.28 \pm 0.08 \% w / w)$ was slightly higher than the previous report $(0.10 \% w / w)$ (Padumanonda et al. 2007). The results suggest that the mature $S$. siamea leaves harvested from Surin province are the best source for herbal recipes. Besides S. siamea young leaves, the young flowers from Surin, Yasothorn, and Roi Et provinces are good raw materials providing high barakol content.

In our study, the barakol content was determined in three herbal recipes referred to as F1, F2, and F3. Our preliminary study showed that $95 \%$ ethanol extract of $S$. siamea gave higher barakol yield than boiling water extract, $0.727 \pm 0.121 \% \mathrm{w} / \mathrm{w}$ versus $0.599 \pm 0.041 \% \mathrm{w} / \mathrm{w}$, respectively. However, in three herbal recipes, boiling water extracts gave higher percent yields (14.67 to $15.44 \%)$ and barakol content $(0.077$ to $0.123 \% \mathrm{w} / \mathrm{w})$ than

Table 2 Result of precision and accuracy studies $(n=3)$

\begin{tabular}{|c|c|c|c|c|}
\hline \multirow{2}{*}{$\begin{array}{l}\text { Concentration } \\
(\mu \mathrm{g} / \mathrm{mL})\end{array}$} & \multicolumn{2}{|c|}{ Precision (\%RSD) } & \multirow{2}{*}{$\begin{array}{l}\text { Spike } \\
\text { amount } \\
\text { ( } \mu \mathrm{g} / \mathrm{mL})\end{array}$} & \multirow{2}{*}{$\begin{array}{l}\text { Accuracy } \\
\text { Recovery (\%) }\end{array}$} \\
\hline & Intra-day & Inter-day & & \\
\hline 2.5 & 1.15 & 1.90 & 2.5 & $101.59 \pm 0.47$ \\
\hline 5.0 & 1.02 & 0.99 & 5.0 & $100.45 \pm 0.45$ \\
\hline 10.0 & 0.85 & 1.40 & 10.0 & $99.25 \pm 0.09$ \\
\hline
\end{tabular}

did $95 \%$ ethanol extracts ( 8.78 to $11.58 \%$ and 0.019 to $0.025 \% w / w)$ as shown in Table 6. For the F1 recipe, $60 \%$ ethanol extract resulted in the highest percent yield (16.45\%) but the lowest barakol content $(0.018 \% \mathrm{w} / \mathrm{w})$. Boiling water extract of F1 showed similar barakol content to water extract at ambient temperature $(0.077$ and $0.075 \% w / w)$, but relatively higher than $95 \%$ ethanol extract $(0.019 \% w / w)$. Thus, boiling water was selected to compare with $95 \%$ ethanol for extraction of the other two recipes, F2 and F3. The F2 recipe showed higher barakol content than the F3 recipe, 0.123 and $0.085 \% w / w$, respectively, in boiling water extracts. In contrast, the F2 recipe showed quite low barakol content $(0.025 \% \mathrm{w} / \mathrm{w})$ and could not be determined in F3 recipe for 95\% ethanol extract. This occurrence may be caused by higher solubility

Table 3 Robustness results

\begin{tabular}{llll}
\hline Condition & Variation & $\begin{array}{l}\text { \%RSD of } \\
\text { peak area }\end{array}$ & $\begin{array}{l}\text { \%RSD of } \\
\text { retention time }\end{array}$ \\
\hline Flow rate $(\mathrm{mL} / \mathrm{min})$ & 0.8 & 0.32 & 0.29 \\
& 1.0 & 0.11 & 0.02 \\
& 1.2 & 1.13 & 0.04 \\
Column temp. $\left({ }^{\circ} \mathrm{C}\right)$ & 23 & 0.98 & 0.02 \\
& 25 & 0.11 & 0.02 \\
Wavelength $(\mathrm{nm})$ & 27 & 0.98 & 0.04 \\
& 243 & 0.06 & 0.02 \\
& 245 & 0.11 & 0.02 \\
& 247 & 0.02 & 0.02 \\
\hline
\end{tabular}


Table 4 System suitability results $(n=6)$

\begin{tabular}{lllll}
\hline Parameters & $\begin{array}{l}\text { Retention } \\
\text { time }\end{array}$ & Peak area & $\begin{array}{l}\text { Theoretical } \\
\text { plates (USP) }\end{array}$ & Asymmetry \\
\hline Mean \pm SD & $30.87 \pm 0.03$ & $\begin{array}{l}1682935 \pm \\
12944\end{array}$ & $102425 \pm 831$ & $1.74 \pm 0.01$ \\
\%RSD & 0.11 & 0.77 & 0.81 & 0.77 \\
\hline
\end{tabular}

of some chemical constituents in herbal recipes than that of barakol, makes less barakol extracted by $95 \%$ ethanol.

The HPLC chromatograms of boiling water extract and water extract of F1 are shown in Figure 2b,c, respectively. Chromatograms of boiling water extract of F2 and F3 are shown in Figure 2d,e, respectively. In addition, HPLC chromatogram of $60 \%$ ethanol showed more peaks (data not shown) indicating presence of other chemical constituents in the herbal recipe. We found similar HPLC chromatogram patterns between boiling water and ambient temperature water extracts, but the different pattern was only between the retention times from 35 to $43 \mathrm{~min}$. This retention time range was consistent with the presence of some chemical constituents of $S$. tora. The result implies that boiling water could extract some chemical constituents in herbal recipes to a greater extent than water at ambient temperature. Thus, in this study, boiling water was the most appropriate solvent for extraction of barakol and other chemical constituents from herbal recipes. Furthermore, Thai traditional medicine uses alcoholic solvent for extraction of the main components from S. siamea and uses boiling water for extraction of $S$. siamea containing formulae. These results indicate that boiling water is appropriate for Thai traditional herbal recipes.

\section{Conclusions}

Barakol, a major substance from S. siamea harvested from Northeast Thailand, was isolated and characterized. This study reported that the average barakol content in mature leaves and young flowers of S. siamea was $0.300 \% \mathrm{w} / \mathrm{w}$. Samples from Surin and Yasothorn provinces yielded the highest barakol content for mature leaves and young

Table 5 Extraction yield and barakol content of mature leaves and young flowers of $S$. siamea harvested from different places in the northeast of Thailand

\begin{tabular}{lllll}
\hline Code & \multicolumn{2}{l}{ Mature leaves } & \multicolumn{2}{l}{ Young flowers } \\
\cline { 2 - 3 } \cline { 5 - 6 } & $\begin{array}{l}\text { Extraction } \\
\text { yield (\%) }\end{array}$ & $\begin{array}{l}\text { Barakol } \\
\text { content (\%) }\end{array}$ & $\begin{array}{l}\text { Extraction } \\
\text { yield (\%) }\end{array}$ & $\begin{array}{l}\text { Barakol } \\
\text { content (\%) }\end{array}$ \\
\hline NR & $10.84 \pm 0.48$ & $0.043 \pm 0.005$ & $10.21 \pm 0.70$ & $0.189 \pm 0.016$ \\
BR & $12.55 \pm 0.63$ & $0.135 \pm 0.034$ & $11.81 \pm 0.48$ & $0.221 \pm 0.003$ \\
$S R$ & $12.57 \pm 0.28$ & $0.617 \pm 0.072$ & $9.97 \pm 0.74$ & $0.296 \pm 0.020$ \\
YS & $13.83 \pm 0.73$ & $0.301 \pm 0.034$ & $15.37 \pm 1.03$ & $0.398 \pm 0.026$ \\
RE & $11.79 \pm 1.04$ & $0.404 \pm 0.057$ & $15.86 \pm 0.82$ & $0.292 \pm 0.042$ \\
Average & $12.32 \pm 1.10$ & $0.300 \pm 0.226$ & $12.64 \pm 2.81$ & $0.279 \pm 0.081$ \\
\hline
\end{tabular}

All data were represented in mean \pm SD $(n=3)$.
Table 6 Effect of solvent types on barakol content of F1, F2, and F3 extract

\begin{tabular}{llll}
\hline Formula & Solvent type & Extraction yield (\%) & Barakol content (\%) \\
\hline F1 & Boiling water & $14.67 \pm 0.34$ & $0.077 \pm 0.006$ \\
& Water & $15.67 \pm 0.94$ & $0.075 \pm 0.010$ \\
& 60\% ethanol & $16.45 \pm 0.69$ & $0.018 \pm 0.001$ \\
& 95\% ethanol & $8.78 \pm 0.39$ & $0.019 \pm 0.004$ \\
F2 & Boiling water & $14.89 \pm 0.19$ & $0.123 \pm 0.004$ \\
& 95\% ethanol & $11.58 \pm 0.31$ & $0.025 \pm 0.004$ \\
F3 & Boiling water & $15.44 \pm 0.19$ & $0.085 \pm 0.001$ \\
& 95\% ethanol & $10.51 \pm 0.90$ & N.D. \\
\hline
\end{tabular}

All data were represented in mean \pm SD $(n=3)$.

flowers, respectively. Furthermore, boiling water was the best solvent for extraction of barakol from S. siamea containing recipes, thus, supporting its use in Thai traditional medicines preparations.

\section{Competing interests}

The authors declare that they have no competing interests.

\section{Authors' contributions}

CM carried out the experiments, acquisition of the data, and drafting of the manuscript. LC and PK helped in the analysis of the results and revision of the manuscript. JS helped in the analysis and interpretation of the data and reviewed the manuscript. KK designed, gave advice on the project, and reviewed the manuscript. All authors read and approved the final manuscript.

\section{Acknowledgements}

The authors would like to thank the Graduate School and Faculty of Pharmacy, Rangsit University, for the financial and facility supports. We greatly appreciate Dr. Siriporn Kittiwisut for the NMR interpretation and Prof. J.E. Moreton, School of Pharmacy, University of Maryland at Baltimore, for his assistance in English language in this paper.

\section{Author details}

${ }^{1}$ Faculty of Pharmacy, Rangsit University, Muang, Pathum Thani 12000, Thailand. ${ }^{2}$ Sino-Thai Traditional Medicine Research Center (cooperation between Rangsit University, Harbin Institute of Technology, and Heilongjiang University of Chinese Medicine), Rangsit University, Muang, Pathum Thani 12000, Thailand. ${ }^{3}$ College of Oriental Medicine, Rangsit University, Muang, Pathum Thani 12000, Thailand.

Received: 18 September 2014 Accepted: 5 February 2015 Published online: 25 February 2015

\section{References}

Chantong B, Wongtongtair S, Nusuetrong P, Sotanaphun U, Chaichantipyuth C, Meksuriyen D (2009) Stability of barakol under hydrolytic stress conditions and its major degradation product. Planta Med 75(4):346-350, doi:10.1055/s-0028-1112206

Leger D, Bayon V, Ohayon MM, Philip P, Ement P, Metlaine A, Chennaoui M, Faraut B (2014) Insomnia and accidents: cross-sectional study (EQUINOX) on sleep-related home, work and car accidents in 5293 subjects with insomnia from 10 countries. J Sleep Res 23(2):143-152, doi:10.1111/jsr.12104

Morphy H, Dunn KM, Lewis M, Boardman HF, Croft PR (2007) Epidemiology of insomnia: a longitudinal study in a UK population. Sleep 30(3):274-280

Padumanonda T, Gritsanapan W (2006) Barakol contents in fresh and cooked Senna siamea leaves. Southeast Asian J Trop Med Public Health 37(2):388-393

Padumanonda T, Suntornsuk L, Gritsanapan W (2007) Quantitative analysis of barakol content in Senna siamea leaves and flowers by TLC-densitometry. Med Princ Pract 16:47-52, doi:10.1159/000096140 
Thongsaard W, Chainakul S, Bennett GW, Marsden CA (2001) Determination of barakol extracted from Cassia siamea by HPLC with electrochemical detection. J Pharm Biomed Anal 25(5-6):853-859

Walsh JK (2004) Clinical and socioeconomic correlates of insomnia. J Clin Psychiatry 65(Suppl 8):13-19

Westerlund A, Bellocco R, Sundström J, Adami HO, Åkerstedt T, Trolle Lagerros Y (2013) Sleep characteristics and cardiovascular events in a large Swedish cohort. Eur J Epidemiol 28(6):463-473

Wongtongtair S, Chanvorachote P, Hutamekalin P, Chaichantipyuth C, Lipipun V, Tiensiwakul P, Meksuriyen D (2011) Barakol-induced apoptosis in P19 cells through generation of reactive oxygen species and activation of caspase-9. J Ethnopharmacol 137(2):971-978, doi:10.1016/j.jep.2011.07.013

Yang Y, Zhang Z, Li S, Ye X, Li X, He K (2014) Synergy effects of herb extracts: pharmacokinetics and pharmacodynamic basis. Fitoterapia 92:133-147, doi:10.1016/j.fitote.2013.10.010

Submit your manuscript to a SpringerOpen ${ }^{\circ}$ journal and benefit from:

- Convenient online submission

- Rigorous peer review

- Immediate publication on acceptance

- Open access: articles freely available online

- High visibility within the field

- Retaining the copyright to your article

Submit your next manuscript at $>$ springeropen.com 